p. 12), is raising funds to engage the considerable brain-power of business. consultants and accountancy experts to produce such a plan. We cannot accept that it is beyond the intellectual resources of the country to devise a better system than the one we have at present.

Dr. Anthony reiterates that G.P.s have neither the time nor the energy to attend meetings after the evening surgery, with the result that the majority are out of touch and decisions are made on their behalf without their knowledge. The G.P.A. is setting up an organization of local groups meeting informally through which every member can express himself, with major issues being decided by postal ballot. In this way it is intended to publish the "Plan for Better General Practice" for discussion and vote.

Dr. Russell refers to the appalling terms and conditions of service to which every doctor wishing to practise under the monopoly N.H.S. has to contract. Few doctors really know what these terms of service are, and certainly very few of the general public have any idea of the "police state" which exists within our ancient democracy and under which doctors have to work. The G.P.A. is making a study of these terms of service and intends to publish them in understandable language to doctors and the general public alike.

The General Practitioners' Association stands for a thorough review of the sys tem of general practice under the N.H.S. -I am, etc.,

Gerald C. Biss, Steering Committee, G.P.A

London E.10.

\section{Children in Hospital}

Str.-Your recent leading article on "Children in Hospital" (October 19, p. 946) points out that the present national statistics do not give a representative picture of the demand; this is an understatement.

This hospital group serves a population of approximately 280,000 . The official figure for children admitted to hospital in 1962 was 728 paediatric cases; the actual figure for the period was 3,291. The 2,563 lost children were hidden as infectious diseases, general surgery, E.N.T., and ophthalmology. Even this enormous discrepancy is less than the truth, as it does not include children admitted direct to major paediatric hospitals nor those to long-stay hospitals.

Although our own regional board has recently made inquiries into the group figures, I am concerned that there is no way in which this information can be obtained on the standard form returned to the Ministry (S.H.3), and it seems clear that figures for children's admissions are equally inaccurate wherever the statistics are compiled.

Facts are urgently needed for planning the future of children in hospitals, and, as Illingworth and Knowelden have shown in another context, ${ }^{1}$ the myth of continually falling demands for children's beds should no longer be allowed to influence decisions. - I am, etc., R. M. FORRESTER.

aediatric Department Royal Albert Edward Infirmary. Wigan, Lancs.

\section{REFERENCB} Illingworth, R. S., and Knowelden, J., Lancet.
1961, 1, 877.

\section{The Gillie Report}

SIR,-The Gillie Report has been generally welcomed as an assessment of most of the sensible if uncontroversial statements on general practice and its future made in recent years, but is it likely to have any far-reaching effect on its development, and can that development be left to evolution from within its ranks? Apart from a few brave experiments in organization, and admittedly with no encouragement from outs'de, general practice has evolved very little since 1948 in spite of considerable changes within its field of work. These include a diminution in the use of surgical skill, an increase in the use of diagnostic investigation, and greatly increased demands in the fields of therapeutics, preventive medicine, and psychiatry, demands which are likely to increase in the future.

Other vital factors in considering future development are the increasing isolation of the family doctor from contact with hospitals and consultants, education, both undergraduate and postgraduate, and the method and level of remuneration. The return of the general practitioner to the hospital as personal doctor to those of his patients under consultant care, and to have some beds of his own with specialist consultation available, would benefit all except those responsible for hospital organization. Postgraduate education would stem from such integration, but should be increasingly available in the form of courses in provincial and teaching hospitals. One hopes that the establishment of chairs of general practice and the trend of thought towards increasing psychiatric training will improve both undergraduate and pre-registration teaching.

The Gillie Report suggests the attachment of midwives and health visitors to practices to integrate maternal and infant care. This could surely be extended to domiciliary care of all types, much of which is duplicated at present. The district nursing service would be of much greater value if integrated with general practice, but could only be a practical proposition in fairly large groups. Far more ancillary help in the form of receptionists, secretaries, and nurses could be utilized to give the practitioner more time for his hospital work, for education, for research, and for outside interests and relaxation.

If the foregoing premises and arguments are accepted there would seem to be only one solution. Group practices where possible would look after, say,
20,000 to 25,000 people, with perhaps ten doctors working from a central surgery, possibly attached to a hospital Each practitioner would retain his own list but might choose to pursue a special interest whether it be obstetrics, gynaecology, dermatology, paediatrics, etc., and be able to give a second opinion in his field in which he would have time to study and perhaps undertake research. The obstetricians in the group would achieve greater experience than the average G.P. obstetrician of to-day and so relieve the consultant obstetrician of much of his worry over the future of maternity care.

It might be argued that the fairest method of remuneration would be by item of service. This would involve greatly increased paperwork, it would be difficult to evolve fair rewards for the great majority of the work, and would be open to abuse. Capitation equally does not reward increased care, but a combination of the two along the lines of obstetric payments might be evoived or loadings might be given to patients in under-doctored areas and to those over 60. To encourage greater use of ancillary help and improved premises and equipment, either these could be supplied by the State or a proportion of expenses could be paid-say, half, with tax relief on the other half. As to the level of remuneration, it would clearly have to be higher than at present to encourage recruitment, prevent drift abroad, and encourage practitioners to develop their future along such lines rather than stagnate in an attempt to survive by limiting expenses.

Clearly rural practitioners could not and probably would not want to evolve in this way, and there need be no compulsion even for urban practitioners to do so. There would be sacrifices to be made, though individuality, freedom, and the doctor-patient relationship need not be among them. The single-handed man would lose some of his god-like control over the health of his flock and the highlist practitioner working for his coronary might suffer a little financially. On the other hand, there would be greater opportunities for discussion with consultants, social workers, and nurses, and far greater integration of all the health services, with consequent benefit to the community.-I am, etc.,

Torquay, Devon.

JoHn C. Lindsay.

SIR,-The Gillie Report makes many recommendations with the object of making general practice (" a specialty in its own right ") a satisfying career. It is therefore surprising to read in your summary of the report (October 5, p. 861):

"Hospital staff appointments, wholeor part-time, for general practitioners are envisaged, and it is believed that 'in the course of a few years general practice, though continuing to be a lifelong career for many, will be for others an experience of 15 or more years leading into adjacent professional fields.'" 